\title{
A CORRELATION COEFFICIENTS ANALYSIS ON INNOVATIVE SUSTAINABLE DEVELOPMENT GROUPS
}

\author{
Ugur Turan \\ Educational Scientific Institute of Economics, Management and International Business \\ National Technical University "Kharkiv Polytechnic Institute" \\ 2 Kyrpychova str., Kharkiv, Ukraine, 61002 \\ uturan55@gmail.com
}

\begin{abstract}
The purpose of this study is to observe the evaluation of all the factors that influence sustainable development, by doing this, the author collected all the logically affecting indicators of 2000-2018 and divided them into 4 groups by affiliation which are Economic and Political, Energy and Environmental, Innovation and Entrepreneurship, Intellect and Social Capital. This paper tries to perform the correlation coefficients matrix analysis to show, how the innovative indicators on sustainable development groups interact with each other, and open by using statistical methods to new views to further studies, in addition, to make the sustainable development activities of the Ukraine's energy enterprise sector more efficient and to pioneer further initiatives.

The significance of the data was realized by using the normalization method, followed by using the Statistica mathematical program, and correlation coefficients were analyzed. At the last step, data were eliminated by applying the Cheddock scale. The data on the matrices that we built shows their noticeable significance and they are presented in this last stage of the study.

According to the results of the study, the relationship between the data in each group has a high standing, and an innovative study has emerged with a statistical perspective.

The resulting outcome demonstrates the connection of various 121 data and diversity between groups.

The contribution of this study is that the results will be developed and reveal an integrated sustainable development mechanism and economic perspective with the final stage of the author's prospected research. This article, as a part of the author's research, plans and provides an alternative viewpoint for energy venture companies within the framework of sustainable development pillars in UNDP.
\end{abstract}

Keywords: sustainable development, energy venture companies, statistical analysis.

DOI: $10.21303 / 2504-5571.2020 .001130$

\section{Introduction}

The concept of sustainability, which tries to find a solution to the utmost vital problems for today's era, means maintaining the ability to produce in general terms in the near future. Global warming, which is one of the peak problems of today, played a role in the emergence of this study. There are numerous areas, affected by global warming, and the sustainable development concept is also of great rank to solve the problems of these areas for the future, because due to the late awareness of countries towards environmental policies, problems have increased today. This research targets the Ukrainian energy enterprise sector within the framework of sustainable development and provides a statistical perspective that supports solving problems that may arise, moreover contributes a diverse outlook to the literature.

In the light of the United Nations Development Program (UNDP), 17 specific criteria have been identified and play a significant role in the development of countries, solving important problems in the world, improving economic prosperity and preventing environmental factors, besides effects to eradicate poverty and inequalities, instilling responsible consumption patterns into individuals and governments, and playing a major role in social, economic and environmental focusing on sustainable development goals, set by countries [1].

The development program, which entered into force on 1 January 2016 and targets the next 15 years, is a global development agenda that criticizes the global system. The aim of the course is to plan a 15-year development plan with the lessons, learned after the 1000-year development goals, combating climate change, creating an innovative structure, building a sustainable production and consumption, adopt peace and justice, economic inequality, which stand out among the sustainable objectives [2]. 
UNDP is in a unique spot to implement its objectives through its work in more than 170 countries and territories. While the world economy grew by $0.001 \%$ in the 1700 s, with the industrial revolution in the $1750 \mathrm{~s}$, economies began to make the visible progress. One of the major factors behind this is the active use of coal [3]. This situation, which completely changes the way of production of countries and producers, and the economic order, has brought out an understanding of growth-based welfare in the world. On the other hand, with the increase in the use of fossil fuels, the economic system that has shaken the social order has emerged and the eco-system has been directly affected. It is well known, that the heavy industry, which developed after the Second World War, focused on the development economy and started to affect the ecosystem [4].

A wake-up movement in the world in the early 1990s made awareness to begin. The Rio summit is the beginning of awareness of the world's major issues and is an important pillar. Among the determined criteria, the economic and social dimensions were mentioned in red and blue colors, respectively. The environmental dimension to be added in the future would take its place in the literature with the green color [5]. The awareness of the problems in the world has increased considerably after 2010. For example, the 1000-year development plan between 2000 and 2015 has worked very well and has been a guide in solving many problems. Poverty in Africa has fallen by half, the proportion of girls, enrolled at school has been increasing, and pioneering the solution to such important social problems has begun.

World Sustainable Development goals of the United Nations have been progressing towards their goals since 2016 and aim to eliminate the issues, such as poverty, hunger, health, education and social equality, which have important problems for the world. For example, contrariwise, with the support of the politicians of the countries, hunger can be eliminated and this is possible, but Poverty and inequality are the main issues that may take time, but it is possible [6]. Innovations can be accelerated to reach the stated targets. Human beings form the basis of sustainable development, and whenever individuals change their consumption patterns and lifestyles, the goals are more easily achieved. For example, it is necessary to investigate how products are produced and to focus on behavioral changes. It is necessary to examine the supply chain in the processes of importing a product, to make it sustainable and to produce policies that will harmonize with nature, economy and social environment. The policies of the countries are on their way to a new form. The concepts of green economy and sustainable economy are included in the policies of states. If economic growth models are being questioned in the world today, one of the most important reasons for this is changing production and consumption paths. It has been recognized, that if consumption is increased without increasing equity, this leads to significant problems, and on this basis, sustainable development objectives are of great importance [7].

While searching the literature for this study, it was seen, that it would be useful to state the key points briefly. The priority of this study is that it addresses a wide range area. In example, to show a significant point, such as climate change, which is one of the most important issues of today, under the name of energy and environment group, this issue has been pressed. The importance of climate change covers many areas, for example, it can affect economic and environmental factors directly or indirectly. Precautions and policies for not to be affected by climate change in the following years both in the field of economy and energy, innovation, etc are necessary. It appeals to many areas in the field $[8,9]$.

As it is known, climate change affects various ranges, it started to bring one after another in numerous problems. Such as, one study demonstrates the effect of climate change on marine safety in transportation areas. In fact, we observe that people, living in these regions, do not make any preparations for climate change and the government focuses on the Arctic region because it poses a risk of emerging [10]. Another study focused on the position of climate change for human health and the concepts of community resilience and risk management regionally [11]. This study was aimed at Chinese agricultural production and it was observed that harvest times were affected by the humidity rate and wind speed due to climate change [12].

Another essential point is new business opportunities or ideas that can be upgraded with innovations and entrepreneurship by using sustainable development models. Focusing on these areas is a vital priority for people or companies, because in an integrated market, the world is not that 
great, and any awareness or innovation leads to further work and earnings [13, 14]. For instance, this study has examined how entrepreneurship will take form for the following years, and has studied digital innovation and digital entrepreneurship concepts [15].

The energy field is crucial for sustainable development. A sustainable economy, such as energy efficiency, is of paramount importance in building a business. Minimizing the economic impacts, brought about by climate change, is focusing on specific areas and issues [16].

The importance of major issues, such as fighting hunger, income inequality, human rights, fighting corruption, and the quality of education must and should be a priority for all countries [17].

Certain pillars, such as the Kyoto Protocol, the Paris treaty, the Rio summit, are of great position in making the world an economically, environmentally and socially sustainable place [18].

One of the main objectives of this study was to identify innovative sustainable development groups with the correlation coefficient analysis and to reveal certain data by elimination. Before reaching this point, the publications in some important literature that use the normalization method in the field of energy, such as [19] were analyzed. The importance of this method will be explained in more detail in the next section.

As a whole, the intention of the author as a result of this study is to present a different point of view by creating innovative groups of sustainability concepts with a standpoint through the statistical analysis. The formation processes of the groups were created and expanded on the basis of UNDP's sustainability goals, and in this article, which is a part of the author's research with indicators from various sources, the Ukrainian energy market problems were targeted, and in this path this study aimed to give the literature an unlike and innovative viewpoint.

\section{Research Materials and Methods}

To the transitory start to this section by explaining the route of the research approaches, there are 4 main titles (Fig. 1) in the model, respectively, Economy and Politics, Energy and Environment, Innovation and Entrepreneurship, Intellect and Social Culture.

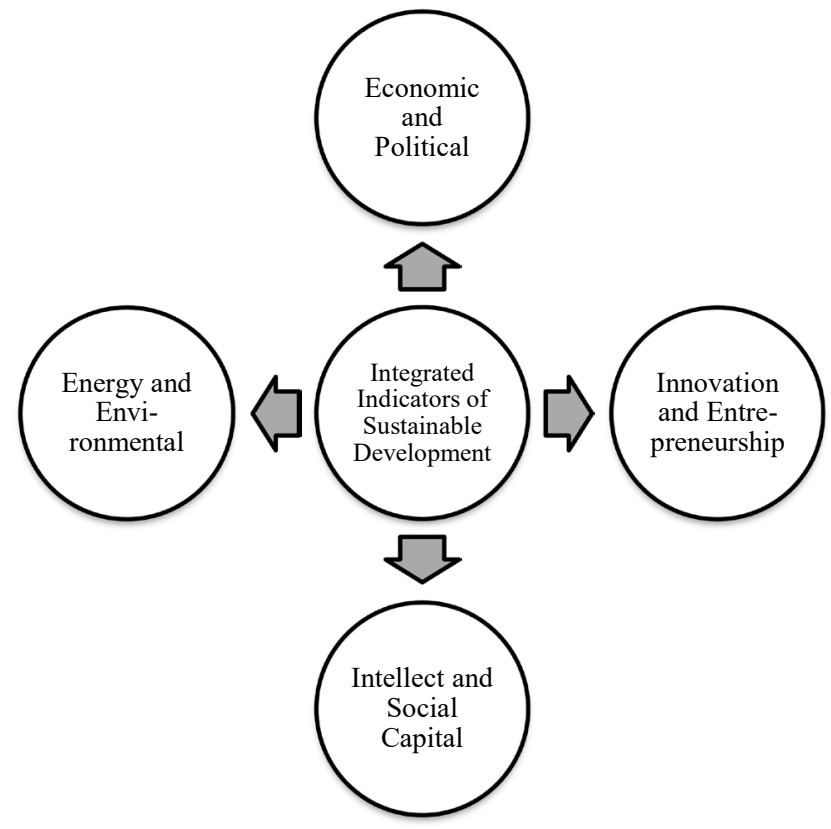

Fig. 1. Innovative sustainable development groups

121 indicators with data for these groups were collected from 3 main places: World Data Banks database, which is called "World Development Indicators", British Petroleum Statistical Data 2019 and Ukrstat. The time interval for the data is from 2000 to 2018 for Ukraine. The study, concentrated on Ukraine, has the potential to be developed and applied to different countries by utilizing further models and indicators. For forecasting between variables and getting particular 
results, the time period was chosen as 18 years. The value of 0.0001 is given for certain years of some indicators without data. This value was decided in accordance with consideration as an inert element. For the analysis, a statistical program was implemented, which is called Statistica 10, our data were normalized by this program according to their minimum and maximum decisions from the perspective of entrepreneurs. As a result, we had obtained the output correlation coefficient matrix form, and in last according to the Cheddock scale, we selected the most fitted indicators among the groups. The route of author's research is shown in (Fig. 2).

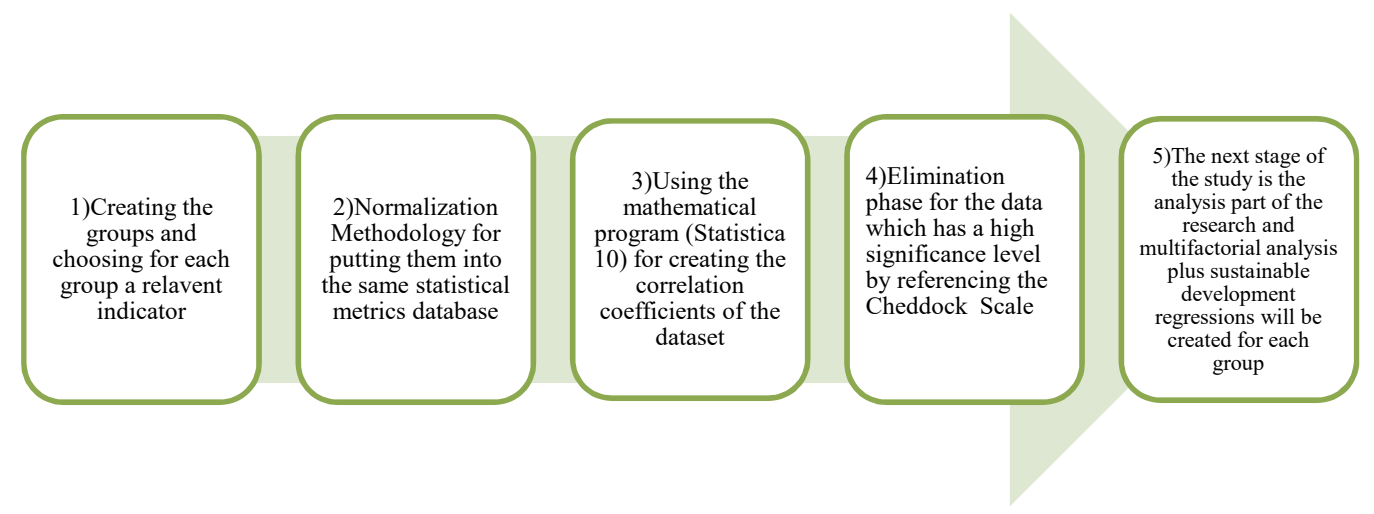

Fig. 2. The visual process of the study

If we examine these stages more deeply to provide a statistical comparison of the 121 data we have, the data are converted into the same type of statistics by the normalization method. While using the normalization method, maximum or minimum values had been calculated, then and formalization was achieved and we obtained new values.

$$
\begin{aligned}
& x i^{\wedge} \llbracket n o r m \rrbracket_{-}=x i / x \max \rightarrow 1 \\
& x i^{\wedge} \llbracket n o r m \rrbracket_{-}=x \min / x i \rightarrow 1 .
\end{aligned}
$$

Following this procedure, for the correlation coefficient analysis, to enlighten briefly; it is used to measure the strength of the connection between two factors. Correlation analysis is a statistical method, used to test the linear relationship between two variables or the relationship of one variable with two or more variables and to measure the degree of this relationship if any. The aim of the correlation analysis is to see, in which direction the dependent variable (Y) changes when the independent $(\mathrm{X})$ changes. As a result of the correlation analysis, a linear relationship and the degree of this relationship, if any, is calculated with the correlation coefficient. The correlation coefficient is indicated by " $\mathrm{r}$ and takes values between -1 and +1 . A positive relationship indicates that if the values of the $\mathrm{X}$ variable increase, the values of the $\mathrm{Y}$ variable increase, or if the values of the $\mathrm{X}$ variable fall, the values of the $\mathrm{Y}$ variable tend to fall. A negative correlation (negative relationship) means that if the values of one of the variables increase, the values of the other variable decrease. The correlation coefficient of " 0 shows that there is no linear relationship between the variables [20].

According to the above descriptions, to start with, it is needed to pick the factors, which might affect a resulting sign. Consequently, we have a matrix of harmonizing correlation coefficients, which is used as the base for an analysis of limitation interdependence which is by using the Cheddock Scale. Then we select limitations, shown in Fig. 3), regularly affecting the resulting sign, and eliminate the parameters with a fragile connection by the situation from the structure. Also, we remove parameters with a high matching correlation coefficient. In last by understanding the Cheddock Scale, it is the one furthermost, generally used in statistics.

This measures the strength and path of a linear relationship between two variables. Values continually range among -1 (solid negative relationship) and +1 (solid positive relationship). Factors 
at or nearby to zero suggest weak or no relationship. Correlation coefficient values, fewer than +0.6 or larger than -0.6 , are not measured significant. According to the research processes and methods, the next chapter describes the outputs and analysis of the data.
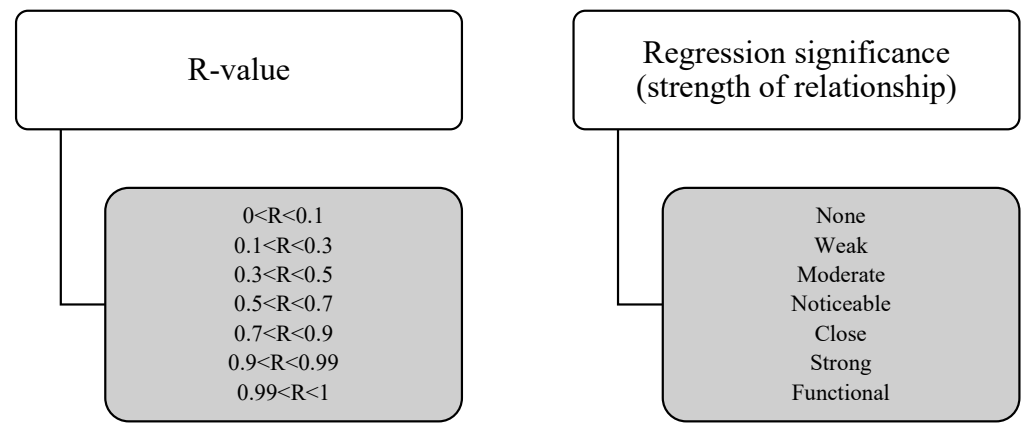

Fig. 3. The Cheddock scale criteria [21]

\section{Results and Discussion}

In this section, there are demonstrated author's research findings. After elimination by using the Cheddock scale, a total of 44 data for 4 groups was obtained according to the coefficient correlations. The variables that stayed in the model are shown below under their groups. Except for the Energy and Environment group, the matrix outputs of the other sets are summarized and the indicators of the energy and environment group have taken place in more detail.

\section{1. Economic and Political Group}

- Imports of goods and services (\% of GDP), $-\mathrm{x} 1$;

- Gross fixed capital formation ( $\%$ of GDP), - x2;

- Exports of goods and services (\% of GDP), - x3;

- Inflation, GDP deflator (annual \%), - x4;

- Tax revenue (\% of GDP), $-\mathrm{x} 7$;

- GDP growth (annual \%), - x9;

- Foreign direct investment, net outflows (\% of GDP), $-\mathrm{x} 10$;

- Portfolio investment, net (BoP, current US\$), - x12;

- Foreign direct investment, net inflows ( $\%$ of GDP), $-\mathrm{x} 13$;

- Real interest rate $(\%),-x 14$;

- Unemployment, youth total (\% of total labor force ages 15-24) (national estimate) - x17;

- Military expenditure ( $\%$ of GDP), - x18;

- Final consumption expenditure ( $\%$ of GDP), $-\mathrm{x} 20$;

- General government final consumption expenditure ( $\%$ of GDP), - x 22 ;

- Dynamic Use of IMF credit (DOD, current US\$), - x26;

- Manufactures imports (\% of merchandise imports), $-\mathrm{x} 30$.

This group is the set, where most indicators remain, it is seen above in Table 1, after the elimination method and, where important indicators are removed as well. When we give an example to this economic and political group, from the point of view of energy enterprise companies, foreign direct investment (net outflows), exports of goods and services, portfolio investment, manufactures imports managed to remain in our matrix system. Consisting of important inputs of a sustainable economy, GDP growth (annual percentage), tax revenue (percentage of GDP), inflation, real interest rates, etc. matrix has taken place in our system. Consisting of important inputs of a sustainable economy, GDP growth (annual percentage), tax revenue (percentage of GDP), inflation, real interest rates, etc. matrix has taken place in our system. From another point of view, to give an example among the data, eliminated according to the Cheddock scale method, current account balance (percentage of GDP), research and development expenditure (percentage of GDP), unemployment (total, percentage of labor force), household's final consumption of GDP), etc. and the analysis of these data will not be done in the next steps, and the analyzer will continue with only the data we have. 
Table 1

Economic and Political Correlation Analysis Results

\begin{tabular}{|c|c|c|c|c|c|c|c|c|c|c|c|c|c|c|c|c|}
\hline & $\mathbf{x 1}$ & x2 & $\mathbf{x} 3$ & $\times 4$ & $\mathbf{x} 7$ & x9 & $\mathbf{x 1 0}$ & $\mathbf{x 1 2}$ & 13 & 14 & 17 & x18 & $\times 20$ & $\mathrm{x} 22$ & 26 & $\mathbf{x 3 0}$ \\
\hline $\mathbf{x 1}$ & 1 & & .40 & 0.14 & 0.11 & .14 & .02 & & I & 0.23 & 0.02 & 24 & 0.03 & 0.51 & .22 & 0.03 \\
\hline $\mathbf{x} 2$ & 0.38 & 1 & -0.13 & -0.14 & -0.12 & 0.53 & 0.21 & -0.24 & 0.59 & -0.13 & 0.58 & 43 & 0.66 & 0.6 & 0.08 & 0.01 \\
\hline $\mathbf{x} 3$ & -0.46 & -0.13 & 1 & -0.09 & -0.18 & 0.35 & -0.49 & 0.35 & -0.41 & 0.14 & 0.13 & .19 & -0.5 & -0.08 & 0 & 0.69 \\
\hline $\mathbf{x} 4$ & 0.14 & -0.14 & -0.09 & 1 & -0.08 & 0.09 & -0.12 & -0.41 & -0.35 & 0.0 & .15 & r & 0.07 & 0.08 & -0.57 & 0.2 \\
\hline $\mathbf{x} 7$ & -0.11 & -0.12 & -0.18 & -0.08 & 1 & 0.03 & -0.12 & -0.03 & -0.21 & -0.01 & -0.22 & -0.39 & 0.32 & -0.41 & -0.13 & -0.26 \\
\hline x9 & -0.14 & 0.53 & 0.35 & 0.09 & 0.03 & 1 & 013 & 03 & 0.07 & -0.18 & 0.48 & 0.29 & -0.62 & 0.32 & -0.47 & 0.22 \\
\hline $\mathbf{x 1 0}$ & 0.02 & 0.21 & -0.49 & -0.12 & -0.12 & & 1 & -0.3 & & 0 & -0.03 & & 0.27 & & -0.07 & 38 \\
\hline $\mathbf{x 1 2}$ & -0.06 & -0.24 & 0.35 & -0.41 & -0.03 & -0.3 & -0.3 & 1 & -0.32 & 0.08 & 0.02 & -0.39 & -0.12 & -0.1 & 0.64 & 0.27 \\
\hline $\mathbf{x 1 3}$ & 0.37 & 0.59 & -0.41 & -0.35 & -0.21 & 0.07 & 0.46 & -0.3 & 1 & 0 & 0.12 & 0.31 & -0.25 & 0.49 & 0.12 & -0.34 \\
\hline x14 & -0.23 & -0.13 & 0.14 & 0.05 & -0.01 & -0.18 & 0.34 & 0.08 & 0 & 1 & -0.11 & -0.12 & 0.05 & -0.17 & $0.0^{\prime}$ & 0.14 \\
\hline $\mathbf{x 1 7}$ & 0.02 & 0.58 & 0.13 & 0.15 & -0.22 & 0.48 & -0.03 & 0.02 & 0.12 & -0.11 & 1 & 0.4 & -0.49 & 0.33 & -0.17 & 0.42 \\
\hline $\mathbf{x 1 8}$ & 0.24 & 0.43 & -0.19 & 0.46 & -0.39 & 0.29 & 0.24 & -0.39 & 0.31 & -0.12 & 0.4 & 1 & -0.24 & 0.64 & -0.35 & 0.1 \\
\hline $\mathbf{x} 20$ & -0.33 & -0.66 & -0.5 & 0.07 & 0.32 & -0.62 & 0.27 & -0.12 & -0.25 & 0.05 & -0.49 & 0.21 & 1 & -0.53 & -0.09 & -0.52 \\
\hline$\times 22$ & 0.37 & 0.6 & -0.08 & 0.08 & -0.41 & 0.32 & 0.13 & -0.1 & 0.4 & -0.17 & 0.33 & 0.64 & -0.53 & 1 & -0.05 & -0.13 \\
\hline$\times 26$ & 0.22 & -0.08 & 0 & -0.57 & -0.13 & -0.47 & -0.07 & 0.64 & 0.12 & 0.07 & -0.17 & -0.35 & -0.09 & -0.05 & 1 & 0.03 \\
\hline $\mathbf{x 3 0}$ & -0.03 & 0.01 & 0.69 & 0.2 & -0.26 & 0.22 & -0.38 & 0.27 & -0.34 & 0.14 & 0.42 & 0.1 & -0.52 & -0.13 & 0.03 & 1 \\
\hline
\end{tabular}

\section{2. Energy and Environment Group's Detailed Indicators}

The first step for the Energy and Environment group, the data selection, has been added to this study. Below in Table 2, it was added to the initial version of the data of this group, the aim for showing the detail indicators is to take attention for a possible sustainable development system that could be a possible example for the energy companies.

Table 2

Selected Energy and Environmental Indicators

\begin{tabular}{cl}
\hline $\mathbf{1}$ & \\
\hline x37 & CO2 emissions from manufacturing industries and construction (\% of total fuel combustion) \\
x38 & CO2 emissions from electricity and heat production, total (\% of total fuel combustion) \\
x39 & Methane emissions (\% change from 1990) \\
x40 & Coal rents (\% of GDP) \\
x41 & Renewable energy consumption (\% of total final energy consumption) \\
x42 & Electricity production from nuclear sources (\% of total) \\
x43 & Electricity production from oil, gas and coal sources (\% of total) \\
x44 & Access to electricity (\% of population) \\
x45 & Energy intensity level of primary energy (MJ/\$2011 PPP GDP) \\
x46 & Energy use (kg of oil equivalent per capita) \\
x47 & Electric power consumption (kWh per capita) \\
x48 & Fossil fuel energy consumption (\% of total) \\
x49 & Alternative and nuclear energy (\% of total energy use) \\
x50 & Energy imports, net (\% of energy use) \\
x51 & CO2 emissions (metric tons per capita) \\
x52 & Total greenhouse gas emissions (\% change from 1990) \\
x53 & Total greenhouse gas emissions (kt of CO2 equivalent) \\
x54 & Agricultural methane emissions (\% of total)
\end{tabular}




\section{Continuation of Table 2}

\begin{tabular}{ll}
\hline $\mathbf{1}$ & \\
\hline x55 & Methane emissions in energy sector (thousand metric tons of CO2 equivalent) \\
x56 & Oil rents (\% of GDP) \\
x57 & Total natural resources rents (\% of GDP) \\
x58 & Natural gas rents (\% of GDP) \\
x59 & Primary Energy: Consumption (Million tonnes oil equivalent) \\
x60 & Nuclear Energy: Generation (Terawatt-hours) \\
x61 & Nuclear Energy: Consumption (Million tonnes oil equivalent) \\
x62 & Natural Gas Production (bcm) \\
x63 & Natural Gas Consumption (bcm) \\
x64 & Coal Production (Million tonnes oil equivalent) \\
x65 & Coal Consumption (Million tonnes oil equivalent) \\
x66 & Oil Consumption (million tonnes) \\
x67 & Electricity generation from oil (Terawatt-hours) \\
x68 & Electricity generation from gas (Terawatt-hours) \\
x69 & Electricity generation from coal (Terawatt-hours) \\
x119 & Current expenditures on environmental protection (in current prices, thsd. UAH) \\
x120 & Air emissions total from stationary sources (Air emissions total, thsd.t) \\
x121 & Renewable share (modern renewables) in final energy consumption percentage (SDG 7.2) \\
&
\end{tabular}

Although this group has 36 indicators, after analyzing the correlation coefficients, according to the result, only 6 data are left, when the Cheddock scale method is applied. This shows us that the relations of the indicators with each other are highly significant.

- Renewable energy consumption ( $\%$ of total final energy consumption), $-\mathrm{x} 41$;

- Primary Energy: Consumption (Million tons' oil equivalent), - x59;

- Natural Gas Production (bcm), - x62;

- Electricity generation from oil (Terawatt-hours), $-\mathrm{x} 67$;

- Air emissions total from stationary sources (Air emissions total, thsd.t), $-\mathrm{x} 120$;

- Renewable share (modern renewables) in final energy consumption percentage (SDG 7.2), $-\mathrm{x} 121$.

As can be seen, among the remaining data after the correlation coefficient analysis in Table 3, the most important indicators are renewable energy consumption, electric generation from oil, air emissions total from stationary sources and renewable share from the modern tech. In the further research's part of the study, it will be studied on what structure these data can benefit the industry.

Table 3

Energy and Environment Correlation Analysis Results

\begin{tabular}{l|cccccc}
\cline { 2 - 8 } $\mathbf{n}$ & $\mathbf{x 4 1}$ & $\mathbf{x 5 9}$ & $\mathbf{x 6 2}$ & $\mathbf{x 6 7}$ & $\mathbf{x 1 2 0}$ & $\mathbf{x 1 2 1}$ \\
\cline { 2 - 8 } $\mathbf{x 1}$ & 1 & 0.07 & 0.33 & -0.37 & 0.22 & 0.57 \\
$\mathbf{x 5 9}$ & 0.07 & 1 & -0.25 & -0.19 & -0.15 & -0.25 \\
$\mathbf{x 6 2}$ & 0.33 & -0.25 & 1 & -0.28 & -0.17 & 0.27 \\
$\mathbf{x 6 7}$ & -0.37 & -0.19 & -0.28 & 1 & 0.37 & 0.08 \\
$\mathbf{x 1 2 0}$ & 0.22 & -0.15 & -0.17 & 0.37 & 1 & 0.44 \\
$\mathbf{x 1 2 1}$ & 0.57 & -0.25 & 0.27 & 0.08 & 0.44 & 1
\end{tabular}

The Energy and Environment group is of great importance in this study, as the main purpose of the study is to provide a ground-breaking sustainable development mechanism and economic 
perspective with an alternative viewpoint to the energy market of Ukraine. This group, which has influenced many fields, can be further developed in future studies and can assist various studies, forecasts, and academic researches. For this development, the final version of the model and the analysis parts are of high significance. As seen in the above stage so far, it gives an innovative perspective for various studies.

\section{3. Innovation and Entrepreneurship Group}

- High-technology exports (\% of manufactured exports), $-\mathrm{x} 75$;

- Time to prepare and pay taxes (hours), - x77;

- Investment in energy with private participation (current US\$), - x82;

- Firms offering formal training ( $\%$ of firms), - x83;

- Firms experiencing losses due to theft and vandalism ( $\%$ of firms), $-\mathrm{x} 84$;

- Patent applications, residents, $-\mathrm{x} 85$;

- Patent applications, nonresidents, $-\mathrm{x} 86$;

- Merchandise trade ( $\%$ of GDP), - x87;

- Employers, total (\% of total employment) (modeled ILO estimate), - x90;

- The share of innovative enterprises in the total number of industrial enterprises, $-\mathrm{x} 92$;

- Financing sources of innovation activities of industrial enterprises (Total sum of expenses, own funds, state budget, non-resident investor, other sources), - x93.

Innovation title, which is one of the most important factors for sustainable development in this century, was combined with entrepreneurship in this study and common indicators were analyzed. According to the results obtained, we observe in Table 4 how important innovation is. For example, high-tech exports, patent applications both residents and non-residents, financing sources of innovation activities of industrial enterprises are some of the vital indicators in this section. Next, an innovative sustainable development mechanism will be created by using these indicators in the author's research studies. As a result, innovation and entrepreneurship are of utmost importance for sustainability, and it has been observed, that the focus of entrepreneurs and policymakers is primarily related to innovative ideas.

Table 4

Innovation and Entrepreneurship Correlation Analysis Results

\begin{tabular}{|c|c|c|c|c|c|c|c|c|c|c|c|}
\hline & $\times 75$ & $\mathbf{x} 77$ & x82 & $\mathbf{x 8 3}$ & x84 & x85 & x86 & $\mathbf{x 8 7}$ & x90 & x92 & x93 \\
\hline$\times 75$ & 1 & -0.5 & 0.32 & -0.26 & -0.05 & -0.41 & 0 & -0.1 & 0.32 & 0.59 & 0.65 \\
\hline$\times 77$ & -0.5 & 1 & -0.25 & 0.19 & 0.2 & 0.44 & -0.47 & 0.58 & -0.06 & 0.22 & -0.69 \\
\hline x82 & 0.32 & -0.25 & 1 & -0.2 & 0.13 & -0.22 & -0.02 & 0.24 & -0.18 & 0.22 & 0.3 \\
\hline $\mathbf{x 8 3}$ & -0.26 & 0.19 & -0.2 & 1 & -0.24 & -0.14 & -0.13 & -0.12 & -0.08 & 0 & -0.25 \\
\hline x84 & -0.05 & 0.2 & 0.13 & -0.24 & 1 & 0.02 & -0.35 & 0.16 & 0.09 & 0.09 & -0.14 \\
\hline x85 & -0.41 & 0.44 & -0.22 & -0.14 & 0.02 & 1 & 0.22 & 0.23 & 0.11 & -0.08 & -0.45 \\
\hline x86 & 0 & -0.47 & -0.02 & -0.13 & -0.35 & 0.22 & 1 & -0.15 & 0.39 & -0.36 & 0.21 \\
\hline $\mathbf{x} 87$ & -0.1 & 0.58 & 0.24 & -0.12 & 0.16 & 0.23 & -0.15 & 1 & 0.06 & 0.22 & -0.22 \\
\hline x90 & 0.32 & -0.06 & -0.18 & -0.08 & 0.09 & 0.11 & 0.39 & 0.06 & 1 & 0.21 & 0.25 \\
\hline x92 & 0.59 & 0.22 & 0.22 & 0 & 0.09 & -0.08 & -0.36 & 0.22 & 0.21 & 1 & 0.27 \\
\hline x93 & 0.65 & -0.69 & 0.3 & -0.25 & -0.14 & -0.45 & 0.21 & -0.22 & 0.25 & 0.27 & 1 \\
\hline
\end{tabular}

\section{4. Intellect and Social Capital Group}

- Current health expenditure (\% of GDP), - x96;

- Total number of apartments (thsd), - x99;

- Total alcohol consumption per capita, - x101;

- Physicians (per 1,000 people), - x103;

- Smoking prevalence, total (ages 15+), - x106;

- Scientific and technical journal articles, - x107; 
- Technicians in R\&D (per million people), - x108;

- Researchers in R\&D (per million people), - x109;

- Population, total, - x110;

- Literacy rate, adult total (\% of people ages 15 and above), - x111;

- Birth rate, crude (per 1,000 people), - x116.

Intellect and Social Capital is also significant for showing the level of the country or the society. As we can see above in Table 5, there is no doubt about how many scientists or technicians the country has, even their alcohol consumption, number of apartments, birth rate, etc; it shows its level of society, intellectual body... This group demonstrates Ukraine's intellect and social interaction of indicators and it shows the growth in 2000-2018 in both social and intellectual structures. Further study will examine the opportunity of their development sustainability.

Table 5

Intellect and Social Capital Correlation Analysis Results

\begin{tabular}{|c|c|c|c|c|c|c|c|c|c|c|c|}
\hline & x96 & x99 & x101 & x103 & x106 & x107 & x108 & $\mathbf{x 1 0 9}$ & x110 & x111 & x116 \\
\hline x96 & 1 & -0.53 & 0.12 & -0.29 & 0.33 & -0.56 & -0.21 & -0.16 & -0.44 & -0.12 & -0.64 \\
\hline x99 & -0.53 & 1 & 0.16 & 0.31 & 0.13 & 0.09 & 0.14 & 0.04 & 0.54 & 0.2 & 0.28 \\
\hline x101 & 0.12 & 0.16 & 1 & -0.08 & 0.36 & -0.25 & -0.2 & -0.23 & 0.25 & 0.12 & -0.16 \\
\hline $\mathbf{x} 103$ & -0.29 & 0.31 & -0.08 & 1 & -0.5 & 0.31 & 0.28 & 0.26 & 0 & 0.08 & 0.3 \\
\hline x106 & 0.33 & 0.13 & 0.36 & -0.5 & 1 & -0.48 & -0.12 & -0.19 & 0.26 & -0.02 & -0.37 \\
\hline $\mathbf{x 1 0 7}$ & -0.56 & 0.09 & -0.25 & 0.31 & -0.48 & 1 & 0.56 & 0.58 & -0.42 & -0.15 & 0.67 \\
\hline x108 & -0.21 & 0.14 & -0.2 & 0.28 & -0.12 & 0.56 & 1 & 0.99 & -0.51 & -0.1 & 0.63 \\
\hline x109 & -0.16 & 0.04 & -0.23 & 0.26 & -0.19 & 0.58 & 0.99 & 1 & -0.59 & -0.09 & 0.66 \\
\hline $\mathbf{x} 110$ & -0.44 & 0.54 & 0.25 & 0 & 0.26 & -0.42 & -0.51 & -0.59 & 1 & 0.19 & -0.1 \\
\hline x111 & -0.12 & 0.2 & 0.12 & 0.08 & -0.02 & -0.15 & -0.1 & -0.09 & 0.19 & 1 & 0.03 \\
\hline x116 & -0.64 & 0.28 & -0.16 & 0.3 & -0.37 & 0.67 & 0.63 & 0.66 & -0.1 & 0.03 & 1 \\
\hline
\end{tabular}

\section{Conclusion}

The contribution of the research is an innovative focus on the UNDP's sustainable development pillars as well as perspective, by using statistical methods and observing. Being prepared, this study, which covers the first four stages of the mathematical part of the author's research, addresses the issue from the viewpoint of energy entrepreneurs, once choosing sustainable development groups according to the personal research.

As a result, the study used 121 selective indicators which greatly complicate the research, afterwards it has been decided to check data's for the presence of mutual influence. Followed by this step, the normalization methodology assisted for building the correlation coefficient matrices for all groups. Based on the Cheddock scale, the most interdependent were identified and some of the indicators were excluded from the groups. After all the statistical stages, it has been observed how innovative data interact with each other and the importance of the groups, formed in line with sustainable development goals. Considering the global warming and climate change problems, the position of the Energy and Environment group draws attention in the study. According to the results, it can be observed that a lot of data in this group are intertwined with each other and specific indicators for an integrated sustainable development mechanism and remain in the group as noticeable according to the Cheddok scale. In the Economy and Politics group, the relationship between the data is not of concrete significance by the analysis in the matrices table. This group, which has the furthermost essential pillars of sustainable development, is significant for the future. The meaning of Innovation and Entrepreneurship, Intellect and Social groups cannot be measured in the sustainability of countries and societies, and when the characteristics of the data are detected, the indicators of both groups will play a major role in creating an integrated sustainable development mechanism.

These indicators will add a different perception to various studies and the sector by assisting in creating a sustainable development mechanism, which will be the final stage of the author's 
research. Furthermore, the utilized methods, developed so far will create with multi-factor analysis an original integrated sustainable development mechanism.

\section{References}

[1] Background of the Sustainable Development Goals. Available at: https://www.undp.org/content/undp/en/home/sustainabledevelopment-goals/background/

[2] Transforming our world: the 2030 Agenda for Sustainable Development. Sustainable Development Knowledge Platform (2015). Available at: https://sustainabledevelopment.un.org/post2015/transformingourworld

[3] Roser, M. (2020). Economic Growth. OurWorldInData. Available at: https://ourworldindata.org/economic-growth

[4] Komulainen, P. (2017). Today's environmental problems sparked by World War II. Available at: https://www.helsinki.fi/en/ news/society-economy/todays-environmental-problems-sparked-by-world-war-ii

[5] Rimmer, M. (2019). Rio 20: who owns the Green Economy? Available at: http://theconversation.com/rio-20-who-owns-thegreen-economy-7742

[6] Inequality, Poverty Eradication. The United Nations. Available at: https://www.un.org/development/desa/socialperspectiveondevelopment/issues/inequality.html

[7] Røpke, I. (2020). Econ 101-In need of a sustainability transition. Ecological Economics, 169, 106515. doi: http://doi.org/ 10.1016/j.ecolecon.2019.106515

[8] Bykova, O., Chuine, I., Morin, X. (2019). Highlighting the importance of water availability in reproductive processes to understand climate change impacts on plant biodiversity. Perspectives in Plant Ecology, Evolution and Systematics, $37,20-25$. doi: http://doi.org/10.1016/j.ppees.2019.01.003

[9] Clift, R. (2007). Climate change and energy policy: The importance of sustainability arguments. Energy, 32 (4), $262-268$. doi: http://doi.org/10.1016/j.energy.2006.07.031

[10] Ford, J., Clark, D. (2019). Preparing for the impacts of climate change along Canadas Arctic coast: The importance of search and rescue. Marine Policy, 108, 103662. doi: http://doi.org/10.1016/j.marpol.2019.103662

[11] Hess, J. J., Malilay, J. N., Parkinson, A. J. (2008). Climate Change. American Journal of Preventive Medicine, 35 (5), $468-478$. doi: http://doi.org/10.1016/j.amepre.2008.08.024

[12] Zhang, P., Zhang, J., Chen, M. (2017). Economic impacts of climate change on agriculture: The importance of additional climatic variables other than temperature and precipitation. Journal of Environmental Economics and Management, 83, 8-31. doi: http://doi.org/10.1016/j.jeem.2016.12.001

[13] Horne, J., Recker, M., Michelfelder, I., Jay, J., Kratzer, J. (2020). Exploring entrepreneurship related to the sustainable development goals - mapping new venture activities with semi-automated content analysis. Journal of Cleaner Production, 242, 118052. doi: http://doi.org/10.1016/j.jclepro.2019.118052

[14] Kardos, M. (2012). The Relationship between Entrepreneurship, Innovation and Sustainable Development. Research on European Union Countries. Procedia Economics and Finance, 3, 1030-1035. doi: http://doi.org/10.1016/s2212-5671(12)00269-9

[15] Berger, E. S. C., von Briel, F., Davidsson, P., Kuckertz, A. (2019). Digital or not - The future of entrepreneurship and innovation. Journal of Business Research. doi: http://doi.org/10.1016/j.jbusres.2019.12.020

[16] Blesl, M., Kober, T., Bruchof, D., Kuder, R. (2010). Effects of climate and energy policy related measures and targets on the future structure of the European energy system in 2020 and beyond. Energy Policy, 38 (10), 6278-6292. doi: http://doi.org/ 10.1016/j.enpol.2010.06.018

[17] Purvis, B., Mao, Y., Robinson, D. (2018). Three pillars of sustainability: in search of conceptual origins. Sustainability Science, 14 (3), 681-695. doi: http://doi.org/10.1007/s11625-018-0627-5

[18] History of UN Climate Talks (2017). Available at: https://www.c2es.org/content/history-of-un-climate-talks/

[19] Jin, H.-S., Choi, B.-H., Kang, J.-K., Kim, S.-I., Lim, J.-H., Song, S.-Y. (2016). Measurement and Normalization Methods to Provide Detailed Information on Energy Consumption by Usage in Apartment Buildings. Energy Procedia, 96, 881-894. doi: http://doi.org/10.1016/j.egypro.2016.09.161

[20] Correlation Coefficient: Simple Definition, Formula, Easy Calculation Steps. Available at: https://www.statisticshowto.datasciencecentral.com/probability-and-statistics/correlation-coefficient-formula/

[21] Sobolev, I., Babichenko, S. (2013). Application of the wavelet transform for feature extraction in the analysis of hyperspectral laser-induced fluorescence data. International Journal of Remote Sensing, 34 (20), 7218-7235. doi: http://doi.org/10.1080/014 31161.2013.817714 